\title{
Formal analysis of
} kinship terminologies and its relationship to what constitutes kinship

\author{
D wight W. Read \\ University of California, L os Angeles
}

\begin{abstract}
The goal of this paper is to relate formal analysis of kinship terminologies to a better understanding of who, culturally, are defined as our kin. Part I of the paper begins with a brief discussion as to why neither of the two claims: (1) kinship terminologies primarily have to do with social categories and (2) kinship terminologies are based on classification of genealogically specified relationships traced through genitor and genetrix, is adequate as a basis for a formal analysis of a kinship terminology. A substantive problem with rewrite rule formalism is identified next. In Part II this problem is resolved when a kinship terminology is viewed from the perspective of a structured, symbolic system in which there is both a symbol calculus and a set of rules of instantiation giving the symbols empirical content. The symbol structure is linked to individuals via culturally specified instantiation of symbols. It is suggested that one's kin are determined through the symbol structure and its instantiation.
\end{abstract}

\section{Key Words}

formal models $\bullet$ genealogical grid $\bullet$ kinship theory $\bullet$ symbolic structure

Probably the only way to give an account of the practical coherence of practices and works is to construct generative models which reproduce in their own terms the logic from which that coherence is generated. Bourdieu (1990: 92)

\section{INT RODUCTION}

Kinship is commonly viewed as based on genealogy. O ne's relatives, it is said, are those with whom one has a geneal ogical connection. This notion of kinship as being based on geneal ogy goes back to W.H .R .Rivers, who defined 'kinship . . . as relationship which is 
determined, and can be described, by means of genealogies' (1924: 53), and has been made explicit by Scheffler and Lounsbury in their comment that '[w]here the distributional criteria are genealogical and egocentric, we speak of relations of kinship' and refer to '[r]elations of genealogical connection' as 'kinship proper ...' (1971: 38, 39). Their view echoes that of Fortes, who also saw the fundamental aspect of kinship to be genealogical connections, since these 'are universally utilized in building up kinship relations and categories' (1969: 52). From this perspective the onus of what constitutes kinship lies, then, in what is considered to be a genealogical relationship, hence on what constitutes a constant aspect of genealogy applicable to all cultures. An obvious candidate for the latter is reproduction - the usual basis for genealogical tracing. According to the primary proponents of a genealogical basis of kinship, geneal ogy has to do with tracing of ancestry, based on the notion of genitor and genetrix, via the culturally specified persons presumed to have a congenital relationship to ego through engendering and bearing children (Scheffler and Lounsbury, 1971: 37-8, 78). Further, according to Scheffler and Lounsbury, sexual intercourse must be 'considered necessary to the processes of engendering and bearing children' (1971: 38, emphasis added) in local theories of reproduction, though sexual intercourse need not be taken as a sufficient condition for engendering and bearing children in those local theories of reproduction (1971: 30, n. 1). Yet there are groups, such as the Yapese, who claim that 'coitus had no role in conception' (Schneider, 1984: 73), though H elmig (1998) has suggested that the Yapese must al ways have bee aware of the relationship between coitus and pregnancy.

What the Yapese meant by the irrelevance of coitus, though, may not be with regard to a 'theory' about conception, in general, but about what is needed to make a Yapese as opposed to simply a member of the species $\mathrm{H}$ omo sapiens; that is, coitus is not what makes a fetus and newborn 'Yapese', but rather it is 'the doing of the male and the doing of the marialang and the active intervention of the thagith . . . and the performance of the woman as a good woman ...' (Schneider, 1984: 74, emphasis in the original) that makes a Yapese child. ${ }^{1} \mathrm{~T}$ his distinction between conception as a general process and conception as it relates to creating a member of one's group has been discussed by Jane G oodale in her ethnography on the Tiwi. She reports that the Tiwi distinguish between the sexual intercourse needed for pregnancy and the dreaming needed for producing a Tiwi child. 'Although theTiwi recognize that either a husband or a lover can make a baby by having sexual intercourse with its mother, they al so assert that such activity alone cannot create a Tiwi child. A T iwi must be dreamed by its father, the man to whom itsmother ismarried, before it can be conceived by its mother' (G oodale, 1994: 138, second emphasis added). Goodale reports that the Tiwi consistently distinguish between the man who made a baby through sexual intercourse and the father of the baby being the man married to the mother. N ot only is the 'father' the man currently married to the mother (see also M alinowski, 1913; Goodenough, 1970) but the critical process for 'making a Tiwi' is thefather =husband's dreaming that informs a pitapitui (unborn individual) the identity of the woman who will give birth to the pitapitui. ${ }^{2}$

While the Tiwi recognize the role of intercourse in pregnancy and thereby satisfy the criterion presented by Scheffler and Lounsbury for what constitutes a genitor, the fact that it is the man married to the mother that is considered to be the father and not necessarily the genitor becomes problematic for asserting a geneal ogical basis constructed around genitors and genetrixes for kinship among the Tiwi. The same problem arises 
REA D Formal analysis of kinship terminologies

with the Kawelka from the Mount Hagen area of New Guinea. Andrew Strathern observes that while semen must mix with the menstrual blood to bind it and form the fetus into which ancestral ghosts implant a soul or spirit, ${ }^{3}$ what makes a fetus into a male as opposed to a female is the ndating passed from fathers to sons. ${ }^{4}$ Unlike the status of the provider of semen as being fixed through time, the ndating will be traced through the mother's husband should she remarry a man from a group other than the group of her husband and "her sons are spoken of as "being with" the ndating of a group other than their original one' (Strathern, 1972: 12). For the Kawelka the definitional problem now arises as to whether it is the man who provides the semen or the man who provides the ndating that should be considered the genitor of a son. If the former, then his status as genitor based upon sexual intercourse is only partial, as his 'congenital relationship' to a son through transmittal of male qualities via thendating apparently terminates upon remarriage of the woman who gave birth to him; if the latter, the genitor need not be a male viewed as having a role in procreation. N either option fits well with a genealogical argument that requires a permanent, congenital relationship established through coitus and conception as the basis of kinship. Yet for other groups, genitors, even when recognized, are not singled out as the basis for genealogical relationships.

For example, Joseph $M$ axwell has argued that for the Inuit of Repulse Bay 'adoptive relationships are considered both "real" and genealogical' (1996: 41), hence a strictly genealogical account based on congenital relationships would somehow have to include adopted children as part of the genealogical universe. We need to ask, then, whether the problem really lies with a genealogical definition that needs refinement, or whether the problem with lack of fit between ethnographic reporting and the genealogical hypothesis lies with the assertion that the basis of kinship is genealogy constructed around genitors and genetrixes established through sexual intercourse.

In Part 1, I argue that the usual al ternative hypothesis of taking a social category view of who constitute one's kin is inadequate, as it does not account for the formal results that have been obtained via rewrite rule analysis that show the logicality of kinship terminologies viewed as a system of symbols. This poses a quandary. The genealogical hypothesis - the basis for the rewrite rule analysis - is not in accord with ethnographic observations and the social category argument is not in accord with the logicality of kinship terminologies demonstrated through rewrite rule analysis. To resolve this quandary it is necessary to examine in detail the assumptions underlying the formalism of rewrite rule analysis. That examination highlights the way in which the rewrite rule analysis fails to be a theoretically grounded, formal account of a kinship terminology viewed as a symbol structure. I argue that rewrite rules are descriptive and not explanatory of the structural properties of kinship terminologies viewed as a symbol system.

W ith this as a background, in Part 2, I discuss a different approach to a formal analysis of kinship terminology structures that is both consistent with ethnographic observation about kin term reckoning and accounts for the descriptive results obtained through rewrite rule analysis. The approach I present in Part 2 distinguishes the empirical structures obtained from genealogical tracing from kinship terminology properties, then brings the framework of genealogical tracing together with that of a kinship terminology structurethrough what I call theinstantiation of kinship terminology symbols. I suggest that we are dealing with two culturally defined constructs, one based on geneal ogical tracing and the other based on the kinship terminology viewed as a formal, 
culturally defined symbol structure. Instantiation of kinship terminology symbols via the fundamental elements of genealogical tracing (genealogical father, genealogical mother) leads to a genealogical perspective on who constitutes one's kin. But instantiation need not be limited to, nor be defined by, genealogical criteria, hence the formalism I introduce allows for a dynamic, changing, culturally grounded basis for who constitute one's kin that need not besubsumed under the specification of one's genealogical relations. H ence there is no need to posit either metaphorical extensions or 'fictive' kin unless, for a particular group, these concepts have cultural salience.

The theory underlying Part 2 is tested through constructing a predicted categorization of geneal ogical kin type products based on the formal analysis of a kinship terminology structure. It is shown, with the American/English Kinship Terminology as an example, that the predicted mapping of kin terms onto a genealogical grid is in complete accordance with the mapping of kin terms onto the genealogical grid obtained through informant comments about the proper use of kinship terms.

\section{PART 1: INADEQUACY OF FORMAL ACCOUNTS BASED ON KINS HIP VIEWED AS SOCIAL CATEGORIES OR GENEALOGICAL CLASSES}

\section{Inadequacy of a social category basis for kinship}

If the claim that kinship is determined by genealogy is suspect, then we must address directly the question: W hat is kinship? O ne al ternative to a geneal ogical basis for kinship has been a social definition whereby kin terms are symbols that represent social categories (Leach, 1958; N eedham, 1962; M CD ougal, 1964; Beattie, 1964). The 'social category' viewpoint has generally been used with reference to systems said to practice prescriptive alliance (Parkin, 1996: 88-9), ${ }^{5}$ such as Australian social systems where an individual is given a social identity in a system of relationships through sections and subsections of 'marriage classes'. From this viewpoint, kin terms are, seemingly, genealogical only by virtue of a happenstance concordance between genealogical reckoning and social categories, not because the categories are fundamentally about genealogy. But if kin terms were simply symbols with definitions based on already determined social categories, as Leach argued in his assertion that 'kinship terms are category words by which the individual is taught to recognize the significant groupings in the social structure into which he is born' (Leach, 1958: 143), then there is no reason to expect that these same terms, when mapped onto a genealogical grid, should be describable in genealogical terms, as was shown by Lounsbury (1965,) with the Trobriand terminology (Buchler and Selby, 1968: 43), among other terminologies. The congruence between social categories and genealogical representation only makes sense if the social categories are constrained in some manner by genealogical criteria. N eedham identified this problem (1971: 4) in his argument for viewing kinship as systems fundamentally having to do with 'allocation of rights and their transmission from one generation to the next' (1971: 3), but provided no explanation for the fact the system so defined can also be described in genealogical terms, even though it is a telling argument against viewing kinship terms as labels for al ready existing socia categories.

\section{Inadequacy of a genealogical basis for kinship}

Rejecting a symbol/category notion of kinship, though, need not imply acceptance of a geneal ogical basis for kin terms and their interpretation. Ethnographic evidence is hardly 
READ Formal analysis of kinship terminologies

supportive, on the face of it, of the presumption that the meaning of kin terms is primarily genealogical (H irschfeld, 1986) and that the extension of kin terms to persons without known (or even presumed) genealogical relationship is metaphorical, or even 'fictive' kinship. The !Kung san, among whom I did fieldwork in the early 1970s, are a case in point. In her ethnography on the !Kung san, Lorna M arshall discussed the way in which two individuals who are strangers to one another establish a kinship relation. The kinship relation, though, is not established by tracing through genealogies, but through a calculation based on the use of kin terms:

G ao [a N yae N yae !Kung san] had never been to Khadum [to the north of the N yae $N$ yae region] before. The !K ung who lived there at once called him ju dole [dole: 'bad', 'worthless,' 'potentially harmful']. He was in haste to say that he had heard that the father of one of the people at K hadum had the same name as his father and that another had a brother named G ao. 'O h,' said the K hadum people in effect, 'so you are Gao's !gun!a ...' (M arshall, 1976: 242).

They determined a kinship relationship, !gun!a, (a person in the name giver/name receiver relationship with ego) through a kin term calculus that did not depend upon a geneal ogical space for its computation. $\mathrm{H}$ irschfeld makes a similar comment about the Toba Batak, who establish the proper use of kin terms through 'reference to how the individuals use other kinship terms ... not how those individuals are genealogically related' (1986: 221) and cites Singarimbun (1975: 147) on the Karo Batak and Kelly (1974: 69) for the Etoro as other cases where a kind of kin term calculus is used to determine relationships. Similarly, Parkin (1996: 94) notes that genealogy is not the only means for determining relationships between two individuals and comments that ' $[t]$ he ethnographic literature is full of discussions of how, when two people meet for the first time, they set about determining their relationship to oneanother' by using kin terms and not genealogy, and cites Vatuk (1969: 96) for an example. Behrens (1984) comments for the Shipibo that ' $\mathrm{K}$ in terms ... are assigned to individuals by tracing only through the terms themselves ... two women used the kin terms they applied to a third individual in order to determine the kin relation between their offspring and that person' (p. 146).

Scheffler and Lounsbury also recognize what they call 'pragmatic kin-class reckoning', but assert that it is simply reflective of the way in which only partial genealogical knowledge is needed to know the proper use of kin categories 'even though the users of the system may not be accustomed to speaking or "thinking" in the abstract of lengthy genealogical chains' (1971: 142, n. 3). Yet in the !Kung san example quoted above, no geneal ogical knowledge is invoked, only a relationship determined solely by reference to the kin categories. In a similar vein, Schneider observes that there is no reason to assume that kin type products are the only way to construct relative products (1984: 63). ${ }^{6}$ But Schneider does not pursue the argument, even though it lies at the heart of the issue of what constitutes kinship and the relationship of a kinship terminology to kinship. In Part II, I take up this topic directly and introduce a theory of kinship terminology structures based on relative products of kin terms, rather than the relative products of kin types. To motivate that theory, though, we need to examine the inadequacy of the formalism of rewrite rule analysis in providing an account of the formal properties of kinship terminology structures despite its descriptive successes. 


\section{Inadequacy of rewrite rule analysis}

Any alternative to the formalism of rewrite rule analysis must be able to achieve at least as much as has been achieved through rewrite rules. The rewrite rules have demonstrated that it is possible to account formally for the distribution of kin types over kin terms when one takes as a given the so-called focal kin types for each kin term. M ore generally, the rewrite rules have demonstrated logicality to kinship terminologies that any formal account must explicate.

The fact that rewrite rules demonstrate how the full range of genotypes asserted to be in the class of genotypes for which the kin term is taken as a class label can be recovered from specification of the purported, primary genealogical sense of kin terms cannot be dismissed lightly. While the underlying, genealogical assumption of the rewrite rules appears to be unsatisfactory, it is possible that the problem lies in our specification of what constitutes genealogical reckoning, not with the formalism of rewrite rule analysis. To put it another way, is the problem that arises with the rewrite rule/genealogical account primarily that a European notion of physical parentage has been mapped onto non-western 'kinship systems' (Schneider, 1984: 193), or isthe problem at a morefundamental level, relating to what we mean by kinship in the first place, hence making the rewrite rule analysis insufficient as a formal account of a kinship terminology?

Although Scheffler and Lounsbury are careful to distinguish between their formal accounts and what might be true at a cognitive level (1971: 136-50), it is evident that rewrite rules must, in some degree, reflect an emic framework if the rules are to be considered as being more than an exercise in formalism. H owever, success in achieving their stated goal for the formal analysis does not justify viewing rewrite rules as reflecting an emic framework. So long as there are no a priori restrictions on the specification of the content or the form of rewrite rules, rewrite rules are what Chomsky (1963) referred to as an unrestricted rewriting system. With an unrestricted rewriting system it is always possible to specify a set of rewrite rules that will precisely recover the full range of kin types for each kin term; viz., specify a rewrite rule on a term-by-term basis that simply says to replace the focal kin type(s) by the full range of kin types for that kin term. $\mathrm{N}$ either Lounsbury nor Scheffler, the two main proponents of rewrite rules for kinship terminologies, provides any a priori limitation on what is an acceptable rewrite rule. H ence, regardless of how kin terms are linked to sets of kin types; that is, whether kin term usage is the basis for making the linkage, or whether one simply makes arbitrary assignments unrelated to actual usage, it is possible to recover the full range of kin types from the primary kin types by some set of rewrite rules. While D 'Andrade noted this problem with using unrestricted rewrite rules, he simply commented that 'it is reassuring that most analyses [of kinship terminologies] can be accomplished with only a few rules' (1970: 112-13). Though reassuring, it also implies that the success of the rewrite rules depends upon a logic underlying the structural form of kinship terminologies that is not expressed in the rewrite rules and is not captured by the formalism of rewrite rule analysis. It is this logic to which we turn in Part 2.

\section{PART 2:THE LOGIC OF KINSHIP TERMINOLOGIES}

The underlying premise for modeling the logic underlying kin terms viewed as constituting a symbol structure is a 'product' that associates with a pair of kin terms another kin term. Thekin term product wasfirst discussed by D. Read (1984) and is defined asfollows: 
D efinition: Let $K$ and $L$ bekin terms in a given kinship terminology, $\mathbf{T}$. Let ego, alter ${ }_{1}$ and alter ${ }_{2}$ refer to three arbitrary persons each of whose cultural repertoire includes the kinship terminology, T. The kin term product of $K$ and $L$, denoted $K o L$, is a kin term, $M$, if any, that ego may (properly) use to refer to alter ${ }_{2}$ when ego (properly) uses the kin term $\mathrm{L}$ to refer to alter ${ }_{1}$ and alter $_{1}$ (properly) uses the kin term $\mathrm{K}$ to refer to alter 2 .

For example, native users of the American/English kinship terminology would agree that if ego (properly) refers to alter ${ }_{1}$ by the kin term Father and alter ${ }_{1}$ (properly) refers to alter ${ }_{2}$ by the kin term $M$ other, then ego may (properly) refer to alter ${ }_{2}$ by the kin term, Grandmother, hence the result of computing the kin term product, Father o M other, would be the kin term, Grandmother (see Figure 1).

For notational purposes, it is convenient to writekin terms with an initial capital letter to distinguish them from kin types. Kin term products will be written from right to left to represent the order in which the terms enter the product ${ }^{7}$ and can be read from left to right with an 'of' replacing the product symbol. Thus for the kin terms, Parent and Child, in the American/English kinship terminology, the kin term product Parent 0 C hild can be read 'Parent of C hild'. The product, Parent o C hild, is the kin term(s) that ego (properly) uses to refer to alter ${ }_{2}$ when ego (properly) refers to alter $_{1}$ as Child and alter $_{1}$ (properly) refers to alter ${ }_{2}$ as Parent, where each of ego, alter ${ }_{1}$ and alter ${ }_{2}$ include the American/English kinship terminology within their cultural repertoire. The notation for kin term products contrasts with the notation for kin type products, where the kin type is usually written using an initial lower case letter and the products are usually written from left to right, with 's' used to replace the kin type product when reading a kin type product. Thus for the kin types, f and d, the kin type product, fd, would be read '(ego's) father's daughter'. N ote that the result obtained from taking a kin type product, in contrast to a kin term product, is assumed to be universal and independent of any particular culture.

The kin term product is a more formal way (cf. K ronenfeld, 1980) of expressing the

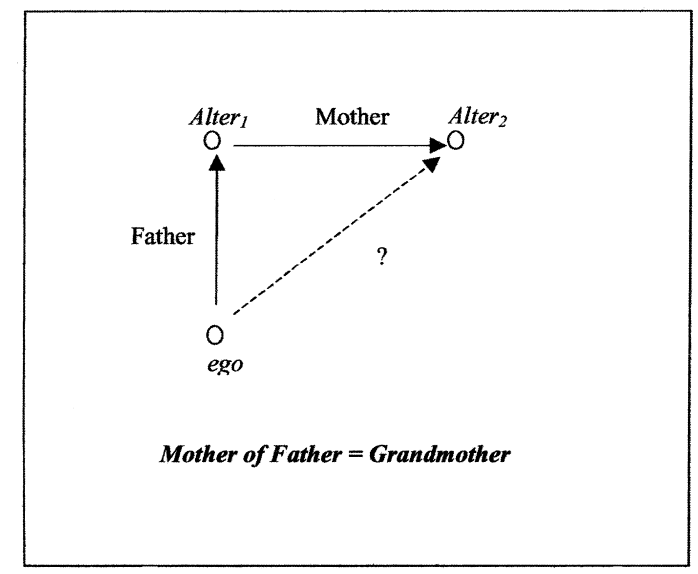

Figure 1. Graph of the kin term product, Mother of Father = Grandmother 
kind of kin term calculus that has been noted by a number of ethnographers, as discussed earlier. It is a way of directly linking kin terms to one another as symbols without first providing an instantiation of the symbols (e.g. via kin types) and without secondly using the instantiated form as the way to determine how one symbol is related to another symbol. Instead, kin terms are related to each other as symbols based on native knowledge about proper use of kin terms.

Whether or not the kin terms, along with the kin term product, form a structure generatable from a set of primary or atomic kin terms by use of certain equations, called structural equations, indicating which kin term products can be reduced to what kin terms is an empirical question. What must be determined for a given terminology is the set of atomic kin terms, the hypothesized structural equations and any other rules that give the structure its form. Then it must be demonstrated that the system so defined does generate a structure isomorphic to a M odel $_{D}$ (Read, 1990) for the kin terms expressed in the form of a kin term map (Leaf, 1971) that displays the way in which the kin terms are interconnected based on cultural knowledge. The beginning point for the analysis, then, is a kin term map ( Model $_{D}$ ) in which are listed all of the kin terms and how the kin terms are interconnected when taking products with the atomic kin terms Read, 1984 , n.d.). The atomic kin terms are determined through the analysis of the kin term structure displayed in the kin term map.

The generation of a structure from atomic symbols and structural equations has two constraints, the reciprocity principle and the focal term property, that distinguish kinship terminology structures from other, possible, symbol structures. The first constraint derives from the notion of reciprocal kin terms; namely, if ego (properly) refers to alter by the kin term $K$ then the reciprocal kin term would be the term $L$ that alter (properly) uses to refer to ego. ${ }^{8}$ The reciprocity of kin terms can also be extended to kin term products and to structural equations. If $\mathrm{K} O \mathrm{~L} 0 \ldots 0 \mathrm{~N}$ is a kin term product, then the reciprocal product would bethe product written in reverse order with each term replaced by its reciprocal term. For example, the reciprocal of the product Parent o Cousin (=U ncle/Aunt) would be Cousin o C hild (=N ephew/N iece) since C hild is the reciprocal of Parent and the reciprocal term for Cousin is Cousin. ${ }^{9}$ The reciprocal equation for an equation would bethe equation constructed by replacing each side of the equation by the reciprocal of that side of the equation. For example, if welet ' 0 ' bea symbol that represents 'not a kin term' then the equation, Parent of Parent of Spouse $=0$ ('Parent of Parent of Spouse is not a kin term'), would have as its reciprocal equation, Spouse of Child of Child $=0$ ('Spouse of Child of Child, or Spouse of G randchild, is not a kin term').

We can now define the reciprocity principle.

Reciprocity Principle: (1) If $\mathrm{K}$ is an element in the symbol structure, then there is an element $\mathrm{K}{ }^{\mathrm{r}}$ in the symbol structure that satisfies the structural definition of a reciprocal symbol and (2) if $E$ is a structural equation for the symbol structure then the reciprocal equation, $\mathrm{E}^{\mathrm{r}}$, is also a structural equation for the symbol structure.

For example, if Parent is a symbol in the symbol structure, then there must be another symbol, call it Child, where Parent and Child, as symbols, satisfy the structural definition for a pair of symbols to be reciprocal symbols. Also, if the equation Parent of Parent of Spouse $=0$ is an equation used to generate the symbol structure, then the 
reciprocal equation derived above, namely Spouse of $\mathrm{C}$ hild of $\mathrm{C}$ hild $=0$, must also be used in the generation of the symbol structure if the resulting structure is to satisfy the reciprocity principle. For the purpose of developing a $\mathrm{M} \mathrm{odel}_{\mathrm{T}}$, we require that the symbol structure we generate does satisfy the reciprocal property.

The second constraint, the focal term property, refers to the way in which a terminological structure has a term from which one may trace to all other kin terms in a kin term map representation of the kinship terminology without using reciprocal tracing. For the American/English kinship terminology this is the kin term, Self. ${ }^{10}$ By using products with the kin terms Father and M other (or jointly, by the kin term Parent) and their reciprocal terms, Son and Daughter (or jointly, by the kin term Child), and the kin terms H usband and Wife (jointly, by the kin term Spouse), all kin terms can be reached by taking products of these kin terms with the kin term, Self, since Self acts as an identity element; that is, Kin Term o Self $=$ Kin Term =Self o Kin Term, for each kin term in the AKT (American Kinship Terminology). ${ }^{11} \mathrm{~A}$ symbol structure will be said to satisfy the focal term property if there is a symbol, $F$, such that (1) all kin term products with the atomic kin terms originate at the kin term $\mathrm{F}$ and (2) every other symbol can be obtained by taking a suitable product of the atomic symbols with the symbol, $F$. We require that symbol structure we are generating satisfy the focal term property.

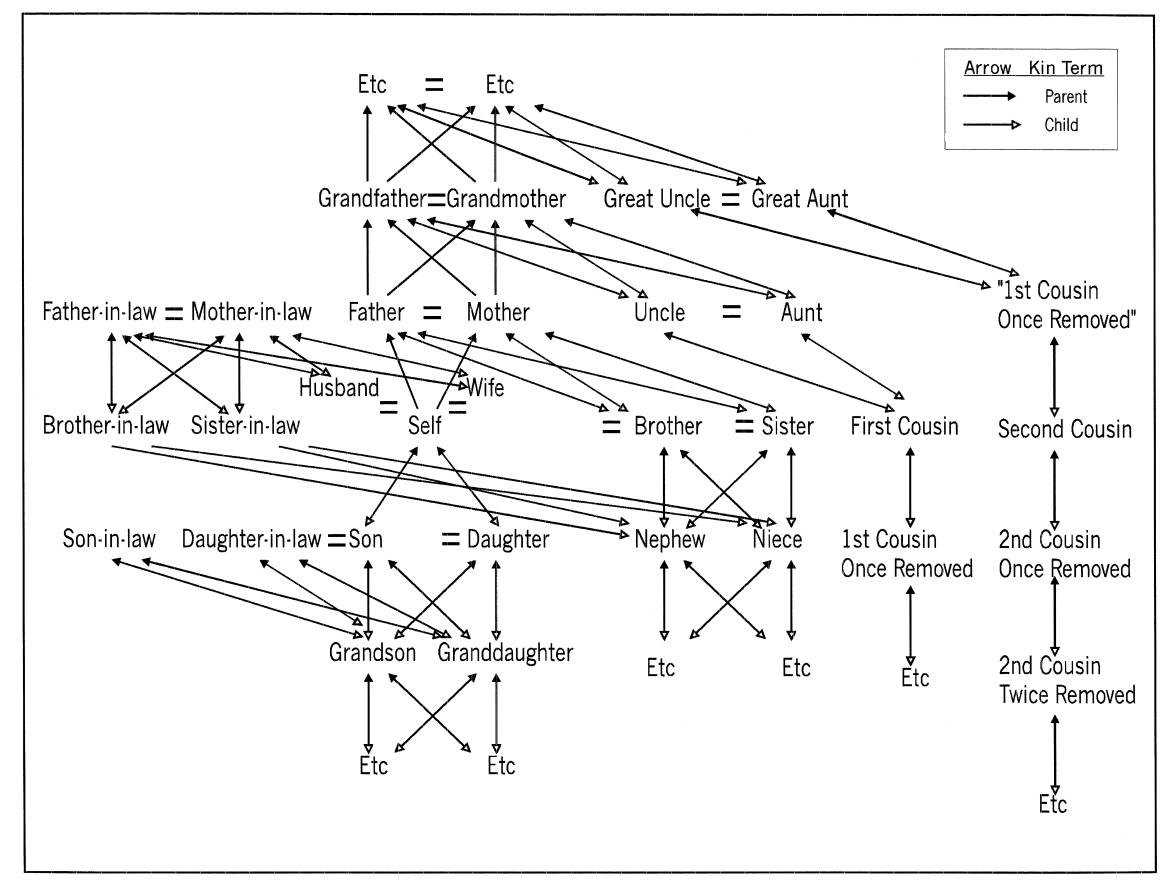

Figure 2 Kin term map for the American Kinship Terminology. Upward arrows represent the result of taking kin term products with the kin term, Parent Downward arrows represent the result of taking kin term products with the kin term, Child. The '=' sign represents the result of taking kin term products with the kin term, S pouse. The nodes labeled with Etc. indicate that the map continues using the same pattem as displayed in the immediately preceding nodes. 
N ow consider how the American/English terminology (see Figure 2 for a kin term map representation of the American/English kinship terminology) can be represented as a symbol structure generated from atomic elements through use of certain structural equations, with the symbol structure satisfying the reciprocity principle and containing a focal term. For the American/English terminology, ${ }_{12}$ the atomic kin terms are determined to be (see Read, 1984; Read and Behrens, 1990):

Atomic Terms: Self, Parent and Spouse.

The term, Self, is an identity term, which also makes it a focal term:

Identity Term: Self.

It is so identified by virtue of the equations that the term, Self, must satisfy to be an identity element, namely Self o Self $=$ Self, Self 0 Kin Term $=$ Kin Term o Self $=$ Kin Term. In order to satisfy the reciprocity principal, a term, call it C hild, must be included, along with the structural equation that determines $\mathrm{C}$ hild to be the reciprocal of the term Parent (see Read, n.d. for a detailed discussion of reciprocal structural equations):

Reciprocal Term: Child

Reciprocal Structural Equation: Parent o Child $=\operatorname{Self}^{13}$ (in theconsanguineal space). (1)

The term, Spouse, is self-reciprocal as determined by:

Structural Equation: Spouse of Spouse $=$ Self.

Both of these equations satisfy the reciprocity principle, as each is a self-reciprocal equation.

Additional structural equations that construct the structural relationships among these elements are shown (Read, 1984, n.d.; Read and Behrens, 1990) to be:

Structural Equations:

Spouse of Parent $=$ Parent

Parent of Parent of Spouse $=0$

(i.e. Parent of Parent-in-law is not a kin term)

Parent of Spouse of $\mathrm{C}$ hild $=0$

(i.e. Parent of Child-in-law is not a kin term)

and

Spouse of $\mathrm{C}$ hild of Parent $=\mathrm{C}$ hild of Parent of Spouse

(i.e. Spouse of Sibling = Sibling of Spouse = Sibling-in-law). 
In order to satisfy the reciprocal principle, the reciprocal equation for each of Equations

(3) and (4) must be included (Equations (5) and (6) are self-reciprocal equations):

\section{Reciprocal Equations:}

Child of Spouse $=$ Child

(the reciprocal equation for Equation (3))

and

Spouse of $\mathrm{C}$ hild of $\mathrm{C}$ hild $=0$

(the reciprocal equation for Equation (4)).

Analysis of the terminology determines that it first consists of a 'consanguineal' structure based on the atomic terms Self and Parent (with its reciprocal, Child) and Equations (1) and (2) (see Figure 3). The distinct symbols for the consanguineal structure are of the form Self, Parent ${ }^{i}$, Child $^{j}$, or Child $^{i}$ Parent $^{j}$, where by Parent is meant $\mathrm{i}$

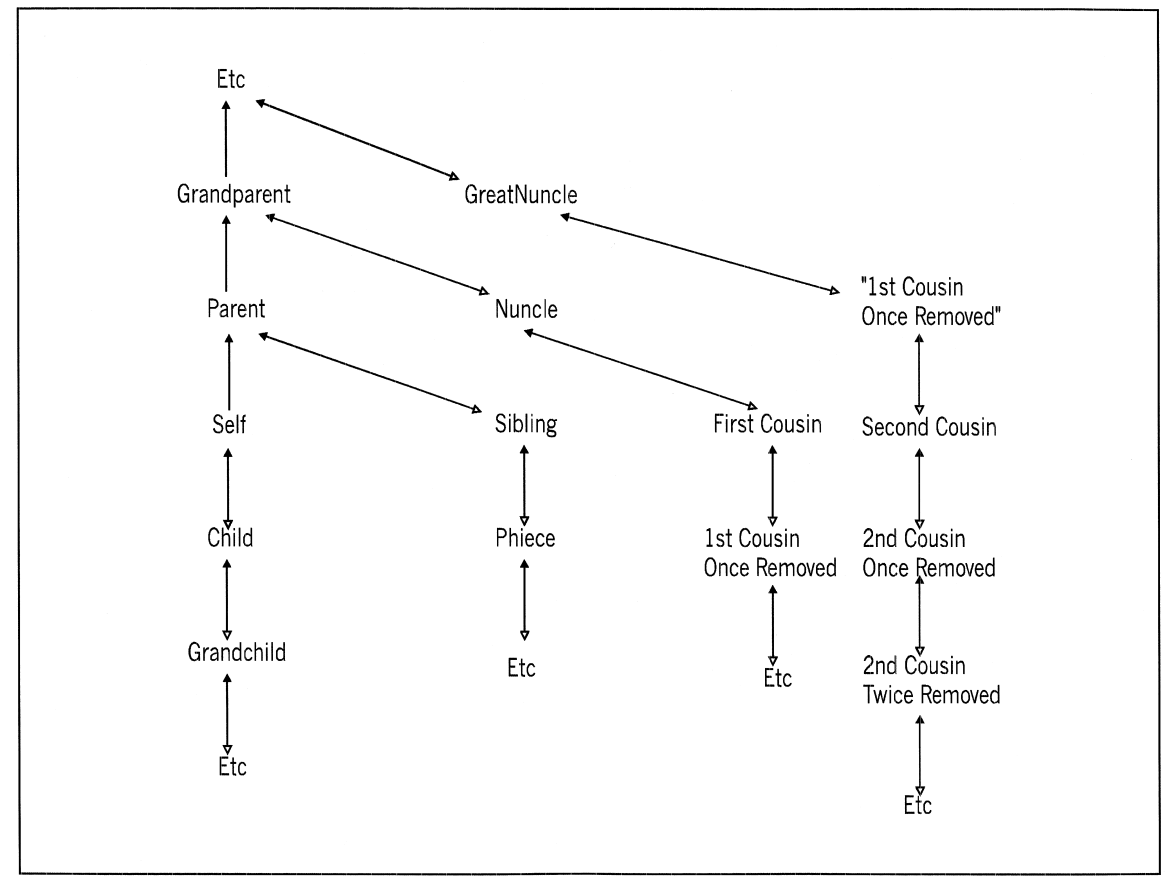

Figure 3. Kin term map for the non-sex marked, consanguineal kin terms for the AKT. Pseudo kin terms, Nuncle and Phiece, have been introduced for the kin term pairs Uncle/Aunt and Nephew/Niece. The terms 1stOnce and '1stOnce' are the same kin term, 1st Cousin Once Removed that occurs at two nodes. The Etc. indicates that there are additional kin terms using the same structural arrangement as the term preceding the Etc. term. 
repetitions of the term Parent, and similarly for the other expressions. ${ }^{14}$ Each of these symbol expressions can be linked to a (consanguineal) kin term; e.g. Parent ${ }^{2}$ would correspond to the kin term, Grandparent. To this consanguineal structure is added the atomic term, Spouse, along with equations (3)-(6) which express the consequence of taking products of the symbols in the consanguineal structure by the term, Spouse.

Some kin terms in the AKT are bifurcated into sex marked kin terms. The rule for so doing is the:

Sex $M$ arking Rule: If (1) $K$ is a kin term and Spouse of $K$ is a kin term, or if (2) $K$ is the reciprocal of a kin term, $T$, where Spouse of $T$ is a kin term, then $K$ is bifurcated into a female marked and a male marked kin term.

For example, Spouse of Parent is the kin term Parent, so the kin term Parent is bifurcated into two sex marked kin terms, namely $\mathrm{M}$ other and Father. Since $\mathrm{C}$ hild is the reciprocal of Parent and Spouse of Parent is a kin term, then Child is bifurcated into two sex marked kin terms, namely Son and D aughter. H owever, Spouse of Cousin is not a kin term, hence Cousin is not bifurcated into sex marked kin terms.

Finally, we account for the labeling of the Cousin terms in the American/English terminology by the:

Cousin Rule: Cousin terms are labeled in such a manner that a maximum number of Cousin terms are distinguished consistent with the requirement that all Cousin terms be self-reciprocal.

The rule needs elaboration. The rule requires that all $\mathrm{C}$ ousin structural position terms (that is, products of the form ChildmParent ${ }^{n}$, where $m, n \geq 2$ ) be self-reciprocal. Selfreciprocity is an extension of the fact that the Cousin terms, First Cousin, Second Cousin, etc. all of which are of the form ChildmParent ${ }^{m}, m \geq 2$, (e.g. First Cousin $=$ Child $^{2}$ Parent ${ }^{2}=$ Child 0 Child 0 Parent 0 Parent $=$ Grandchild 0 Grandparent, or in words, First Cousin is Grandchild of Grandparent) must be self-reciprocal as a consequence of their structural form (that is, the reciprocal of the product C hildmParent $^{m}$ is also ChildmParent ${ }^{m}$ since both exponents are the same number). W hen the exponents are not the same, the "ith Cousin $\mathrm{j}$ times removed" nomenclature preserves "distance" (the smaller of the exponents, $m$ and $n$, minus 1 makes the term an ith Cousin term) and makes the terms self-reciprocal (the absolute value of $m-n$, denoted in mathe matical notation by $|m-n|$, is the " $\mathrm{j}$ " in " $\mathrm{j}$ times removed" part of the term). For example, the kin term $3^{\text {rd }}$ Cousin twice removed $=\mathrm{Ch}$ ild ${ }^{5}$ Parent ${ }^{3}=\mathrm{Child}^{3}$ Parent ${ }^{5}$ since $3=($ smaller of 4,5$)-1$ and $2=5-3$ for each of the products, Child ${ }^{5}$ Parent ${ }^{3}$ and Child ${ }^{3}$ Parent ${ }^{5}$. The nomenclature also maximizes the number of distinct C ousin terms, since each product of the form ChildmParent ${ }^{n}, m<n$, is given its own label, ${ }^{15}$ namely "ith Cousin $\mathrm{j}$ times removed," where $i=m-1$ and $\mathrm{j}=|\mathrm{m}-\mathrm{n}|$.

The symbolic system so defined (see Figure 4) is a M odel $_{T}$, as it has been based on a theory of kinship terminologies as having a symbol structure that can be generated from atomic symbols along with appropriate structural equations and where the structure so generated must also satisfy both the reciprocal principle and the focal term property. The M odel $_{T}$ has a structure isomorphic to the kin term map (M odel ${ }_{D}$ ) for the American/ 


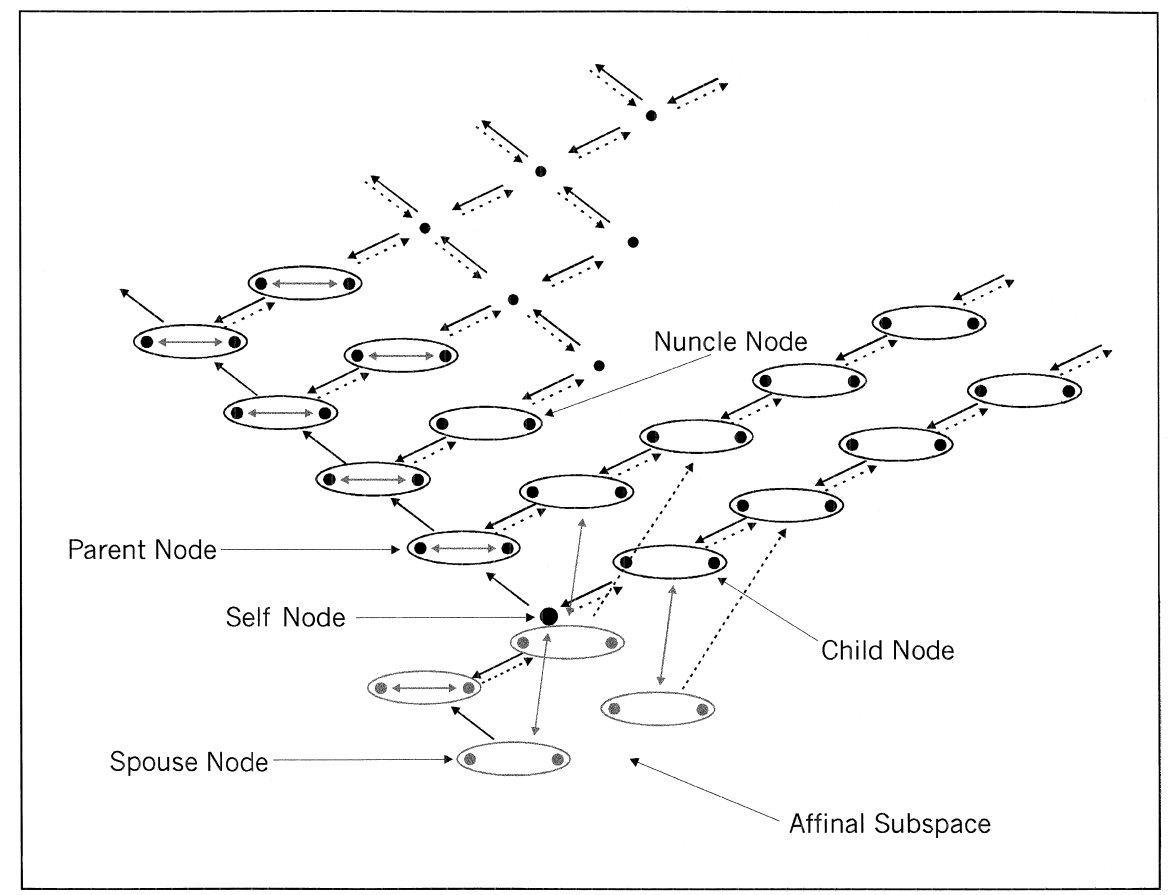

Figure 4. Graph of the algebraic structure isomorphic to the kin term map for the AKT. The nodes for the generating symbols, S elf, Parent, $C$ hild and $S$ pouse are indicated with arrows. The latter three nodes are bifurcated into two nodes due to the rule for sex marking of symbols. The gray nodes in the bottom part of the graph form the affinal subspace and are precisely the nodes marked with an 'in-law' suffix when the algebraic structure is mapped to the kin term map.

English kinship terminology shown in Figure 2 (Read and Behrens 1990; Read n.d.), hence serves as an explanation for that $M_{\text {odel }}{ }_{D}$. It now remains to show how the distribution of kin types for the kin terms in the American/English terminology can be recovered from the symbolic system and its structure.

To do so, let us make the following instantiation of the atomic kin terms with respect to kin types:

$$
\begin{aligned}
& \text { Self } \rightarrow\{\text { ego }\} \\
& \text { Parent } \rightarrow\{f, m\} \\
& \text { Child } \rightarrow\{s, d\} .
\end{aligned}
$$

For the sex marked forms of the atomic terms we make the following instantiations:

$$
\begin{aligned}
& \text { Father } \rightarrow\{f\}, \\
& \text { M other } \rightarrow\{m\}, \\
& \text { Son }->\{\{\},
\end{aligned}
$$


ANTHROPOLOGICALTHEORY 1(2)

and

D aughter $\rightarrow\{d\}$

In addition, we introduce the following two kin type product equations: ${ }^{16}$

$$
\begin{aligned}
& \mathrm{b}=\mathrm{fs}=\mathrm{ms} \\
& \mathrm{z}=\mathrm{fd}=\mathrm{md} .
\end{aligned}
$$

We construct the range of kin type products for each kin term by use of a set product for a pair of sets in which the product of each term in a set is made with each of the terms in the second set. For the kin terms Parent, Grandmother and Cousin we have:

(1) Parent $\rightarrow\{m, f\}$,

(2) Grandmother $=$ M other 0 Parent

$$
\rightarrow\{m, f\} \times\{m\}=\{m m, f m\}
$$

(with the order of the sets in the set product reversed from the order of the kin terms in the kin term product for $\mathrm{G}$ randmother, since kin type products are written from left to right and kin term products are written from right to left) and

(3) Cousin $=$ Child o Child o Parent o Parent

$\rightarrow\{m, f\} \times\{m, f\} \times\{s, d\} \times\{s, d\}=\{m m s s, m f s s, f m s s, f f s s, m m s d, m f s d, f m s d, f f s d$, mmds, mfds, fmds, ffds, mmdd, mfdd, fmdd, ffdd \}

$=\{m b s, f b s, m b d, f b d, m z s, f z s, m z d, f z d\}$.

Figure 5 displays the mapping of the American/English kinship terms onto the usual geneal ogical grid as predicted from the construction of kin type products for kin terms based on the symbol structure and the instantiation of the atomic kin terms given here. The set of predicted mapping is completely correct, hence the construction has succeeded in accounting for the distribution of kin type products for the kinship terms. The formalism based on viewing the kinship terminology as a symbol structure thus includes within it the results obtained through the formalism of rewrite rules, hence is a more encompassing theory, at least for the American/English terminology.

The construction not only provides $\mathrm{M}_{\mathrm{M}}$ odel $\mathrm{I}_{\mathrm{T}}$ isomorphic to the $\mathrm{M}_{\mathrm{Ode}} \mathrm{D}_{\mathrm{D}}$ and accounts for the distribution of kin type products over thekin terms, but also accounts for a property of the American/English kinship terminology that heretofore has been considered either an anomaly - namely the lack of the '-in-law' suffix on the terms used to refer to one's parent's siblings - or problematic by virtue of the way in which the Uncle/Aunt terms depend upon a disjunctive definition from a genealogical perspective. The 'anomaly' is found to be explicable as a property deriving from the properties of the symbol structure that has been constructed. A logical implication of Equation (6) is that the equations, Spouse o Uncle = Aunt ('Spouse of Uncle is Aunt') and Spouse of Aunt 


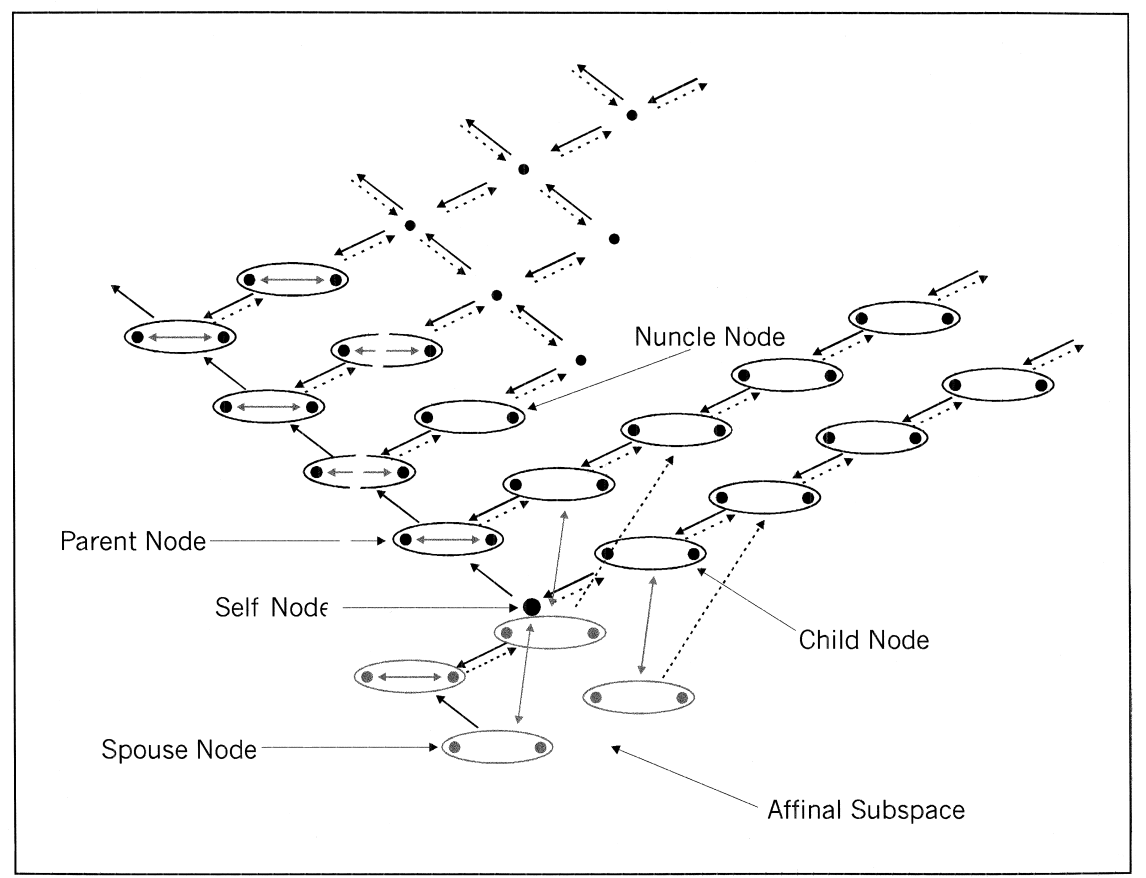

Figure 5. Genealogical diagram for the AKT as predicted from the algebraic structure shown in Figure 3 and the mapping from symbols to kin types defined by $\mathrm{Self} \rightarrow\{$ ego $\}$, Parent $\rightarrow\{m, f\}, C h i l d \rightarrow\{d$, s $\}$ and S pouse $\rightarrow\{w, h\}$

$=$ Uncle, must be true. ${ }^{17} \mathrm{~T}$ he same logic applies to the kin terms G reat . .. G reat Uncle and $G$ reat ... G reat Aunt. Consequently, the way in which the consanguineal kin term, Uncle (Aunt) is also used for affinal (genealogical) relatives is explicable as kin term usage consistent with the underlying logic of the kin term structure. There is no need to appeal to non-terminological properties to account for the seeming anomaly of not using a term with the suffix '-in-law' for Spouse of Aunt (Spouse of Great Aunt, etc.) and Spouse of Uncle (Spouse of Great Uncle, etc.), contrary to the argument of Schneider (Schneider, 1980: 107, n. 7) that the lack of an -in-law suffix has to do with affect.

The disjunctive definition, with its attendant problems as discussed extensively by D 'Andrade (1970), arises only because of features of the genealogical grid onto which kin terms are mapped. The local, structural relation of Aunt to U ncle is the same as the structural relation of $M$ other to Father, namely both pairs of terms satisfy the equation, Spouse of $X=Y$. Disjunctiveness does not arise for the Mother/Father pair in the genealogical grid only because of the assumption that in the genealogical grid 'If a'schild- isc, and b's-child-isc, then a's-spouse-is b (all children are legitimate)' (D 'Andrade, 1970: 92); that is, within the genealogical grid, ego's mother's spouse must be ego's father, where ego's father is the genitor of ego. Further, the term Stepfather prevents the disjunctivity that would arise in the case when ego's mother has, in fact, divorced and remarried if the term Father were to be used by ego for ego's mother's new husband, for then Father could refer either to ego's genitor or ego's mother's husband (Read, 1984). 
Thus the problem with disjunctivity that has been associated with the Aunt/U ncle terms is not a feature of these terms, but simply a consequence of the way in which the symbol structure interfaces with the genealogical grid. ${ }^{18}$

\section{The logic behind kinship terminology properties}

As has been shown with the American/English kinship terminology, modeling a kinship terminology as a symbol structure appears to be an effective way to account for properties of a kinship terminology. In this section we will outline, for another terminology, a wide range of features that seem to be the logical consequence of the underlying structure. The terminology to be considered is that of the Shipibo Indians of Peru. The example will also illustrate the way in which terminologies that are radically different at the surface level of kin terms may share structural commonality at a deep, structural level.

The Shipibo terminology (see Figure 6 for a kin term map representation of the Shipibo consanguineal terminology) has a number of features that make it inconsistent

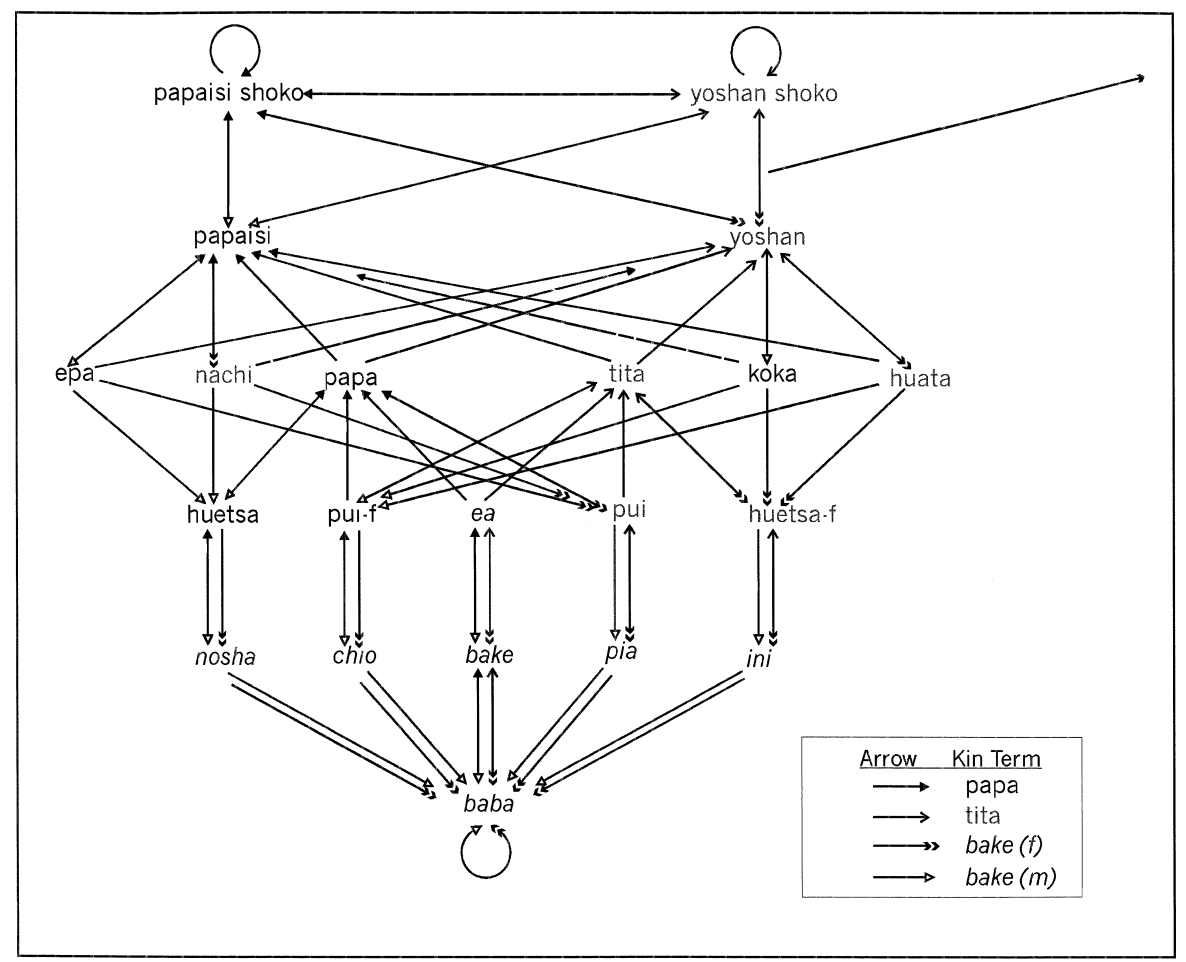

Figure 6. Kin term map for the S hipibo terminology. Upward arrows represent taking products with the atomic kin terms papa (= 'Father') and tita (= 'Mother'). Downward arrows represent taking kin term products with the kin term bake. The '-f' indicates a kin term used by a female speaker. The same term without the '-f' is the kin term used by a male speaker. The terms epa and nachi are used by male speakers and the terms koka and huata are used by female speakers. The terms bake and 'bake' are a single kin term but with two forms to indicate that there is a covert, sex marked form of bake (=child). 
READ Formal analysis of kinship terminologies

with M urdock's classification of kinship terminologies (Behrens, 1984: 139-47). At the grandparental level the terminology takes on a classificatory aspect with the same kin terms (Papais for males and Yoshan for females) used for siblings of (genealogical) grandfather and grandmother. The 'sibling' terms (see Table 1) are used for all genealogical cousins (parallel or cross) and the terms used for children of 'brother'/ 'sister' are distinguished by sex of speaker but not by sex of child. Similarly, the term for children of ego are not distinguished by sex and are referred to by the single term, Bake. At the grandchild level there is a single term, Baba used for all persons for whom ego would use a kin term at this generational level. The pattern for the kin terms where sex of speaker is a feature is shown in Table 1.

The analysis of the Shipibo terminology establishes that its atomic kin terms are the terms Ea ('Self'), Papa ('Father') and Tita ('M other') along with the single reciprocal term, Bake ('Child') for Papa and Tita (Read and Behrens, 1990; Read, n.d.). In place of the equation, Parent 0 C hild =Self, the Shipibo terminology has the analogous equations Papa 0 Bake $=\mathrm{Ea}$ for male marked kin terms and Tita 0 Bake $=\mathrm{Ea}$ for female marked kin terms. It follows that the underlying structure for the male marked (or for thefemalemarked) kin termsisisomorphic to the consanguineal structure for the underlying structure for the American/English kinship terminology based on the atomic terms, Self and Parent (and reciprocally, C hild) and the structural equation Parent 0 Child =Self. The Shipibo terminology differs from the American/English terminology, however, by use of the equations

$$
\text { Bake o Papa o Papa o Papa = Papa o Papa }
$$

and

Bake o Bake o Papa o Papa = Bake o Papa

for reducing the male substructure generated through use of the kin terms Ea, Papa and Bake, and by use of the equations

Bake o Tita o Tita oTita $=$ Tita o Tita

and

Bake o Bake o Tita o Tita = Bake o Tita

Table 1. Shipibo kinship terms dependent upon sex of speaker

\begin{tabular}{lll}
\hline Gloss & Female speaker & M ale speaker \\
\hline 'Uncle' & Koka & Epa \\
'Aunt' & Huata & N achi \\
'Same sex sibling/cousin' & Pui & Pui \\
'O pposite sex sibling/cousin' & Huesta & H uesta \\
'Child of same sex sibling/cousin' & Ini & N osha \\
'Child of opposite sex sibling/cousin' & Chio & Pia \\
\hline
\end{tabular}


for reducing the female substructure generated through use of the terms Ea, Tita and Bake. The effect of the first equation in each of these two sets of equations is to collapse what would be collateral kin terms onto lineal kin terms, hence giving the terminology a classificatory aspect. The effect of the second equation in each pair of equations is to identify 'C ousin' terms with 'Sibling' terms. It is these four equations, along with male marked and female marked atomic terms, that accounts for the structural differences between the American/English and the Shipibo terminologies despite sharing a common structure at the deep level of atomic terms and structural equations, namely Parent 0 Child $=$ Self, for the Americn/English terminology and its sex marked form, Papa o Bake $=E a$, for the male marked Shipibo kin terms (or, equivalently, the equation Tita o Bake $=\mathrm{Ea}$, for the female marked Shipibo kin terms).

Since the Shipibo terminology has atomic kin terms that are al ready sex marked, there is no need for a rule that identifies when kin terms will be sex marked. Further, the structural position for a 'Cousin' term is identified with the structural position for a 'Sibling' term, hence there is no rule for labeling of 'Cousin' terms as occurs in the American/English terminology. The 'affinal equation', 'Sibling of Spouse' = 'Spouse of Sibling', al so applies to the Shipibo terminology.

Under the instantiation

$$
\begin{aligned}
& \text { Ea } \rightarrow\{\text { ego }\}, \\
& \text { Papa } \rightarrow\{f\}, \\
& \text { Tita } \rightarrow\{\mathrm{m}\}
\end{aligned}
$$

and

$$
\text { Bake } \rightarrow\{s, d\}
$$

the distribution of kin type products over the kin terms in the Shipibo terminology is predicted with complete accuracy (Read n.d.). In addition, as the process of constructing the full Shipibo terminology unfolds, the features of the terminology regarding sex of speaker shown in Table 1 are found to arise as a way to resolve what otherwise would be an anomaly when the genealogical interpretation of thekin terms is worked out under the instantiation given here. Briefly, only when ego is bifurcated into male ego and female ego will there be, for all of the kin terms, a consistent instantiation of the kin terms. M ore precisely, when the above instantiation is used to map kin terms to kin type products, more than one kin term is mapped to a single kin type product for some of the kin terms. ${ }^{19}$ That anomaly is removed when ego is either labeled male or labeled female. That is, when ego is labeled male, say, then the mapping of kin terms to kin type products maps at most one kin term to a kin type product. Further, for those terms where the two mappings so constructed (one based on a male ego, the other based on a female ego) each yield the same kin type product for a kin term, the sex of ego does not affect the usage of those particular terms. The terms so identified in the algebraic analysis are precisely the terms where, in fact, kin term usage is independent of the sex of speaker. In addition, all of the terms where the two mappings differ with regard to the kin type associated with a kin term are precisely those terms for which the sex of 
REA D Formal analysis of kinship terminologies

speaker does, in fact, make a difference in usage. Finally, the number of distinct terms so determined through the al gebraic construction matches the empirical data. M ore precisely, the algebraic construction implies that there will be two 'sibling' terms with the usage of these two terms dependent upon the sex of speaker. The Shipibo terminology does have two 'sibling' terms where the usage depends upon the sex of speaker (see Table 1). Further, the algebraic constrution implies that there will be four terms (two marked as male terms and two marked as female terms) whose usage depends upon the sex of speaker and that are applicable to persons who are siblings of parents. In fact, the Shipibo terminology has four such terms distinguished by sex and whose usage depends upon the sex of speaker (see Table 1). Finally, the analysis predicts that there will be four terms used for 'child of sibling', dependent upon sex of speaker for usage and the Shipibo terminology has four such terms (see Table 1). In all cases the pattern of usage predicted from the structural analysis matches the actual pattern of (proper) usage.

To summarize, it is logically necessary that certain of the symbols distinguished in the symbol structure have instantiation (in terms of kin types) through use of a sex marked ego to avoid the problem of having more than one kin term being mapped to the same kin type and conversely, all kin terms where sex of speaker is identified as critical to the usage of a kin term are so identified through the structural analysis of the terminology. $N$ ote that the instantiation does not assume sex marked egos for the instantiation of the term, Ea. Instead, the bifurcation of ego into male ego and female ego arises in order for the instantiation to be carried out fully in a consistent manner so that no more than one kin term is mapped to a single kin type product.

Just as the lack of an '-in-law' suffix for the term corresponding to Spouse of Aunt or Spouse of Uncle is explicable through the logic of the symbol structure for the American/English kinship terminology, the dependence of terms such as Pui and H uetsa on sex of speaker for their usage in the case of the Shipibo is also explicable through the logic of the symbol structure underlying the Shipibo terminology and the instantiation of the kin terms via kin types. Rather than viewing these as features that require their own, specific explanation, they are, instead, a consequence of how a kin term structure is generated and instantiated. The Shipibo example is particularly striking in that the terms where the sex of speaker affects kin term usage can be recovered solely from the logic of the symbol structure in conjunction with logical consistency in the instantiation of the kin terms via geneal ogical father and genealogical mother.

TheShipibo example is of particular interest, as it implies that while the symbol structure can be identified and analyzed without reference to a geneal ogical interpretation of kin terms, and while the kin terms that depend upon sex of speaker for their proper usage are distinguished as distinct terms through the logic of this symbol structure, the usage of the latter set of terms, with their dependency on sex of speaker in some cases, arises through a genealogical instantiation of the kin terms. The symbol structure distinguishes the terms, but the need to identify sex of speaker as a feature for their proper usage does not arise until a genealogical instantiation is made of the kin terms and the logic of that instantiation as implied by the symbol structure is worked out. The Shipibo example suggests that one property of kinship terminological systems may be consistency with genealogical tracing. H owever, the direction of the consistency is from terminological structure to instantiation of the atomic kin terms using primary kin types, not from a genealogical 'grid' to kin terms as argued by Lounsbury and Scheffler. 


\section{Instantiation of symbols and kinship}

The last observation suggests that one's kin are determined through the instantiation of the symbols in the symbol structure. Contrary to Rivers' claim that kin terms are defined through genealogical specification, the kin terms have relationships as symbols via the symbol structure of which they are a part. It is the symbol structure that then determines which kin terms correspond with what kin types when an instantiation of the atomic kin terms is made using genealogical father and genealogical mother (see Figure 7). Further, a kinship terminology can have alternative (cultural) instantiations so long as the instantiation is carried out in a manner consistent with the logic of the terminological structure. ${ }^{20}$ For example, were we to (culturally) instantiate the kin term, Child, in the American/English terminology by 'adopted child' in addition to 'birth child', consistency would require that a person who is an adopted child would reckon kin terms in a manner no different than a birth child. Thus a 'birth child' would call an 'adopted child' by the kin term Brother or Sister; a person a 'birth child' would call Aunt would call the 'adopted child' by the kin term N ephew or N iece, and so on. ${ }^{21}$

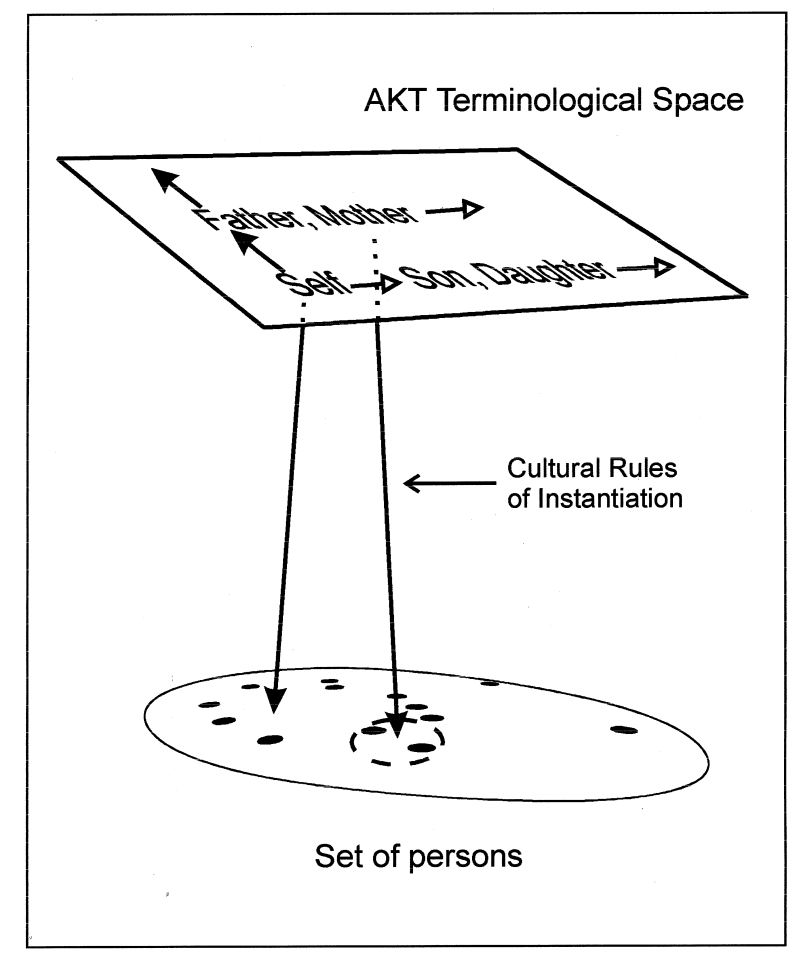

Figure 7. Diagram illustrating the mapping of AKT kin terms viewed as symbols onto a set of persons via cultural rules that specify how the symbols should be instantiated. The left arrow indicates that the kin term, Self, has been mapped to a person (ego), and the pair of symbols, Mother and Father, have been mapped to two persons circled with a dashed line. No a priori claim is made as to the genealogical relationship (if any) of the latter two persons to ego; e.g. the two persons might be the two persons ego calls Mother and Father, respectively, by virtue of adoption. 
READ Formal analysis of kinship terminologies

If, then, we view one's kin as those persons for whom kin terms may properly be used, where 'proper use' is determined through culturally specified rules of instantiation for the kin terms, what does this imply about genealogy and genealogical tracing with regard to kinship? AsParkin (Parkin, 1996) hascommented, genealogical tracing isa way to provide greater specificity of the relationship of one person to another than can be done through specification via the kin term categories. G enealogical tracing is also something that most people find quite easy to do without detailed instruction (Lehman and W itz, 1974). But geneal ogical tracing and the geneal ogical grid that has been the basis of rewrite rule analysis are not the same thing, and failure to distinguish between these two constructs has created a confusion between the fact that tracing only depends upon recursive use of dyadic links, whereas the geneal ogical grid is a symbol structure constructed from primitiveelements, a product (kin type products) and structural equations (Read, 2001), hence is a structure whose relevance to a given cultural context must be demonstrated and not assumed. G eneal ogical tracing is dependent only upon a culturally specified (dyadic) link of each person to a male person and to a femal eperson purportedly in somekind of ancestor/descendant relationship. Whether the link represents genetic father/genetic mother, genitor/genetrix, pater/mater, or whatever is not critical for the process of tracing. Tracing uses simple recursion from an initial person along whatever paths are identified as one repeatedly repeats the process of linking the current, focal person to a male person or to a female person by the culturally specified criterion for asserting a pair of dyadic links between the pair of persons in question. Whether the tracing constitutes genealogical tracing depends upon a logic with regard to what claims about linkages are valid with regard to geneal ogical tracing, e.g. the same perso cannot be claimed to be both male and female in two dyadic linkages (see Atkins, 1974; Lehman and W itz, 1974, for a more detailed discussion of the logic of genealogical tracing). $H$ ence it suffices for genealogical tracing to identify a genealogical father and a genealogical mother, as suggested by Lehman (thisissue), for each person so that tracing may bedonerecursively. The criterion by which someone is culturally specified to be a geneal ogical father or a genealogical mother is not needed for the process of geneal ogical tracing.

In contrast, the genealogical grid is based on the set of primitive symbols, \{ego, f, m, $b, z, s, d\}$, the kin type product, and the structural equations

$$
\begin{aligned}
& f s=m s=b, \\
& f d=m d=z,{ }^{22} \\
& s f=d f \\
& s m=d m \\
& b z=z \\
& z b=b \\
& s b=s=d b \text { and reciprocally, bf =f=zf }
\end{aligned}
$$

and

$$
\boldsymbol{s}=\mathrm{d}=\mathrm{dz} \text { and reciprocally, } \mathrm{bm}=\mathrm{m}=\mathrm{zm}^{23}
$$


(see Read, 2001, for a more extensive discussion of the genealogical grid and its relationship to tracing via genetic father/mother and genitor/genetrix). Further, the kin types $f$ and $m$ are generally assumed to be the genitor and genitrix of ego, respectively, thereby also introducing, for the genealogical grid, a presumption about the universality of genitor and genetrix as culturally salient categories - a universal ity that is not needed for geneal ogical tracing.

Unlike genealogical tracing, the genealogical grid 24 is an abstract structure that requires instantiation for its usage. It is the latter that is problematic for claims about the universality of the geneal ogical grid. D o all cultures both conceptualizea genealogical grid and provide rules of instantiation for its primitive elements? Instantiation is not automatic by virtue of procreation unless one also claims that the male and female involved in coitus are, necessarily, the objects for the instantiation of, say, the primitive symbols, $f$ and $m$. That, of course, is the claim made by Scheffler and Lounsbury. By making that claim, Scheffler and Lounsbury neatly sidestepped the problem of instantiation of the symbols used in the genealogical grid. But the ethnographic evidence, as discussed earlier, seems to suggest that that is too strong a claim. If so, the genealogical grid is not universal and so kinship cannot be constructed on the basis of the properties taken as underlying the genealogical grid. Rejection of the genealogical grid does not, however, deny genealogical tracing. The genealogical grid, though, is necessary for the argument that kin terms are labels for classes of kin type products. The class label argument does not, of course, apply to genealogical tracing.

What we seem to be left with, then, is two levels at which relations between individuals are considered. First is the level of relations identified through genealogical tracing (however the dyadic linkages might be culturally defined) and where there is no a priori structure other than the dyadic relations upon which the tracing is based. We can identify the male and female used in genealogical tracing as the genealogical father and the genealogical mother, respectively. The second is the highly structured set of relations determined through the kinship terminology. The latter intersects with the former in that the set of persons identified through instantiation of the symbols in the kinship terminology intersects in a non-empty manner with the set of persons identified through geneal ogical tracing - hencethe possibility of simultaneous use, as discussed by Parkin (1996), of both categorical specification via kin terms and a more detailed specification based on genealogical tracing.

Finally, the instantiation of the kin terms allows for flexibility in term of who are considered kin within the framework of the kinship terminology. Instantiation must be culturally specified, and whilethere may be a consistency constraint as discussed earlier with regard to how kin terms are used once the instantiation is specified, there is no constraint from the viewpoint of the symbol structure as to the content of the instantiation. The only constraint on content relates to what, culturally, might be deemed as a valid instantiation; hence there is no need to introduce concepts such as metaphorical extension or fictive kin when the instantiation includes persons without a known (or even without any) geneal ogical relationship to ego. $0 \mathrm{r}$, the criterion for instantiation may use an aspect unrelated to genealogy, such as residence, as seems to occur with some of the groups in N ew Guinea (Langness, 1964). Instantiation can both change over time (cf. M. Strathern, 1992) and use different rules at the same point in time. The latter allows for a context based specification of who are one's kin, hence a way to accommodate 
READ Formal analysis of kinship terminologies

observations such as those of A. Strathern, who noted that for the M elpa of N ew G uinea, in a ceremonial context a speaker would assert he is a "true" cross-cousin because he lives near to his kin and is their regular and generous exchange partner' (1973: 32), yet in other contexts the same person might assert that someone 'is not my true (i.e. immediate genealogical) cross-cousin, we call each other by this term only because we exchange pigs and shell valuables' (1973: 32).

\section{Notes}

1 The idea that it is the work done by the male and by the female that is responsible for producing an offspring has also been noted by A. Strathern for the Kawelka in $\mathrm{N}$ ew Guinea. H owever theK awelka, unlike the Yapese, consider intercourse as essential to the initial formation of the fetus (Strathern, 1972: 9).

2 Scheffler (1978: 5-13) has reviewed the assertions that various Australian groups are ignorant of physiological fathers, hence do not have a concept of genitor, and argues that closer reading of the ethnographic evidence does not support such assertions. $\mathrm{H}$ owever, what appears to be consistent is a bifurcation between pregnancy due to sexual intercourse and the entry of a 'spirit-child' into the fetus; that is, a distinction between the general process of impregnation as a feature of creating a member of the species Homo sapiens versus becoming a member of one's group - the local equival ent of a 'Tiwi child'. The latter seems to be consistently viewed as the critical aspect and for this reason the 'physical paternity is normally dismissed as being virtually of no practical importance' (Strehlow, 1971: 596, as quoted in Scheffler, 1978).

3 This theory of procreation is reported to occur with the Trobrianders as well, for they claim that 'semen acts as a coagulant of menstrual blood, producing a clot which a spirit child (baloma) enters ... and which proceeds to grow' (Powell, 1956: 277, quoted by Leach, 1966: 48; see also Austen, 1934). Yet the Trobrianders were al so reported by $M$ alinowski to assert that 'T he seminal fluid does not make the child. Spirits bring at night time the infant . ..' (M alinowski, 1932: 160). Powell considers these different viewpoints as 'coexistent indigenous beliefs which though by European standards [are] mutually contradictory, as are the clan and sub-clan myths of origin, are not so in terms of Kiriwinan logic, since they relate to what $M$ alinowski might have termed different contexts of situation ...' (Powell, 1956: 277). As suggested by Goodale's comments on the Tiwi, the context difference may relate to whether the context is procreation being viewed as a process shared with other animals versus procreation as a process by which a Trobriand child is created.

4 According to $\mathrm{A}$. Strathern, the Kawelka distinguish between the role of semen in uniting with the menstrual blood to make a fetus (Strathern, 1972: 9) and the 'maleness' passed from father to son via the ndating. M ales alone can possess ndating (Strathern, 1972: 11). The distinction is remarkably parallel to the difference between a sperm as the agent that initializes fertilization of the egg and the $Y$ chromosome carried by the sperm that is responsible for maleness. Like the ndating, the Y-chromosome is responsiblefor maleness and is only found in males. But unlike theY-chromosome, the ndating traces back from a son to male ancestors via the man currently married to his mother; i.e. it violates the basic premise of geneal ogy based on reproduction. 
5 Parkin has argued that restricting a category approach to societies based on alliance systems misjudges the universality of categories as constituting a 'linguistic principle' relevant to all 'human thought and speech' (1996: 105). Parkin argues for both a category approach and a geneal ogical approach, with the former providing the conceptual basis for kinship and the latter both a mode of analysis and a means for individuals to provide greater specificity than can often be achieved solely by reference to a category.

6 Buchler and Selby made a similar comment about Lounsbury's success in assigning kin types to Trobriand kin terms when they observed that his success 'does not assure us ... that kinship systems are uniquely and best analyzed as genealogical codes; it is simply that we have not developed techniques as adequate for the display of other kinds of dimensions in the analysis of kinship' (1968: 20)

7 Products are usually written left to right to match the order in which the elements enter into the product; e.g. $2 \times 4$ indicates that one begins with the number 2 , then multiplies the number 2 by the number 4 . Kin type products have traditionally al so been written in 'left to right' notation. A deliberate choice was made to write kin term products in 'right to left' notation so as to permit a simple reading of kin term products that distinguishes them from kin type products. By writing kin term products from right to left, they can be read as if they are text, with the binary product, 0 , replaced by 'of'. Thus $\mathrm{F}$ o $M=$ Father $0 \mathrm{M}$ other $=\mathrm{G}$ randfather would be read 'Father of M other is Grandfather' and refers to how the symbols Father and $M$ other are related as symbols, namely Father of $M$ other equals $G$ randfather as kin term products in the American/English terminology and not to the result of tracing kin type products in a genealogical grid. Southwold (1971) and Atkins (1974) use the same right-to-left convention for their respective notational systems. $N$ ote that kin term products are necessarily culture specific in terms of their calculation, whereas kin type products are defined in terms of a geneal ogical grid, hence are 'culture free'.

8 Although the reciprocals of kin terms may beelicited from informants, from the perspective of developing a theory of kinship terminologies as symbol structures, the reciprocal of a given symbol needs to be expressed in terms of relationships among symbols and not be imposed via externally derived labeling of symbols. The formal, structural definition for the reciprocal of a symbol/term is given in Read and Behrens (1990) and Read (n.d.). It should be noted that the formalism of rewrite rules presumes that reciprocity has al ready been built into a $\mathrm{M}$ odel $_{D}$ for the terminology. The rewrite rule formalism considers pairs of terms to be reciprocal by virtue of the genealogical reciprocal of the kin type products included within the genealogical range for one term in the pair to be the range of kin type products for the other term in the pair.

9 If the symbols also have sex marking, the computation of reciprocals becomes more complex by virtue of the fact that a symbol may have more than one reciprocal; e.g. the kin term Father may have as its reciprocal either the kin term Son or the kin term $\mathrm{D}$ aughter. For a more complete discussion and formal definition of reciprocity of kin term symbol products when some of the symbols have sex markings, see Read (n.d.).

10 That Self should be considered a kin term in the American/English kinship terminology is not self-evident. Some authors such as Atkins (1974) include Self as a kin 
READ Formal analysis of kinship terminologies

term (see Figure 2, Atkins, 1974), while others do not include Self as a kin term. The logic of the structural analysis of the American/English terminology makes it evident that Self must at least be a covert, if not an overt, kin term. O ne of its key properties is that it acts as an identity element for kin term products.

It should be noted, though, that the argument for inclusion of Self as a kin term in the American/English terminology does not imply that all terminologies have a term that is the structural equivalent of Self. The Trobriand terminology has no structural position comparable to the Self of the American/English terminology and no such symbol is needed for the logical completeness of theTrobriand kinship terminology symbol structure.

$11 \mathrm{M}$ ore precisely, $\mathrm{K}$ in term o Self $=$ Self, for if ego refers to alter ${ }_{1}$ by Self and alter ${ }_{1}$ refers to alter ${ }_{2}$ by Kin term, then alter ${ }_{1}$ is actually ego and so ego refers to alter ${ }_{2}$ by K in term. A similar argument justifies the equation Self o K in term $=K$ in term.

12 Space does not permit presenting the analysis used to justify the kin term structures discussed here. The interested reader should consult Read (1984) for an algebraic analysis of the American Kinship Terminology. The algebraic analysis has been implemented as a computer software program, Kinship Analysis Expert System KAES), and the program is described in Read and Behrens (1990) and Read (n.d.), along with the results derived for the American/English, the Shipibo and the Trobriand terminologies. The KAES program may be obtained from the author at dread@anthro.ucla.edu.

13 In general, for users of the AKT, if ego refers to alter ${ }_{1}$ as $C$ hild and alter ${ }_{1}$ refers to alter $_{2}$ as Parent, then ego could refer to alter ${ }_{2}$ as Self or as Spouse since alter ${ }_{2}$ could either be ego or ego's spouse. The analysis of the American/English kinship terminology demonstrates that the complete structure is generated first from a consanguineal structure based on the atomic terms, Self and Parent (and reciprocally, C hild) and the equation Parent of Child = Self, and secondly by expanding this structure through addition of the Spouse symbol. The equation, Parent of Child = Spouse, does not apply to the consanguineal structure since the symbol, Spouse, is not included in the consanguineal structure. For the consanguineal structure, the proper equation is C hild of Parent $=$ Self. O nly after the consanguineal structure is generated is the structure expanded by adding the Spouse symbol along with the structural equations involving the Spouse symbol.

14 Southwold (1971) almost identifies this symbol structure in his formal consideration of what constitutes kinship. Atkins (1974) develops a system of relative products (based on symbols glossed as 'is a parent of' and 'is a child of') essentially identical to that of Southwold. They differ, though, in their goals. Whereas Southwold uses the formalism to provide a definition of kinship, Atkins links his formalism directly to genealogical tracing through requiring the parenthood relation to be a 'dyadic, irreflexive, antisymmetric, nontransitive, and many-many relation for which the informal gloss "is a parent of" is anthropologically acceptable ... [and with converse] "is a child of" ' (1974:3).

15 The more recent collapsing of all Cousin terms by many Americans to the single term, Cousin, is also consistent with self-reciprocity, but minimizes the number of distinct cousin terms.

16 The two kin type definitions are not needed for the construction of the range of kin 
type products for each kin term, but are introduced to keep the construction consistent with the usual manner in which kin types are presented, namely that $b$ (brother) and $z$ (sister) are considered primary kin types.

17 This may be shown as follows: Spouse of Uncle/Aunt = Spouse of Child of Parent of Parent $=$ (Spouse of Child of Parent) of Parent $=($ C hild of Parent of Spouse) of Parent [from Equation (6)] $=$ Child of Parent of (Spouse of Parent) $=$ Child of Parent of Parent [from Equation (5)] =Uncle/Aunt.

$18 \mathrm{D}$ isjunctivity arises in the symbol structure when the binary product maps a pair of symbols, $X$ and $Y$, to more than one symbol. An example is the term, $2^{\text {nd }}$ Cousin Once Removed in the American/English terminology since Child of $2^{\text {nd }}$ Cousin O nce Removed $=2^{\text {nd }}$ Cousin or $2^{\text {nd }}$ Cousin Twice Removed (see Figure 2 ).

19 The same problem arises with the American/English terminology for the Spouse terms, $\mathrm{H}$ usband and Wife. U sage of these two terms depends upon sex of speaker. The algebraic construction maps both of these terms to the kin type product, ego's spouse, when ego hasno sex specification. By introducing the sex of ego, the anomaly is removed and the algebraic construction then maps $\mathrm{H}$ usband to female ego's spouse and W ife to male ego's spouse, but sex of ego makes no difference in the mapping of any of the other kin terms to kin types.

20 Lehman (this issue) has al so noted the role of consistency with kin term calculations as a criterion for being a member of one's kinship domain.

21 It might be objected that the 'Step-' and ' $\mathrm{H}$ alf-' form of kin terms in the American/English terminology would seem to violate consistency in application. Read (1984) has argued that the 'Step-' and 'H alf-' nomenclature appears to be a way to resolve the intersection of the kinship terminology with actual situations that violate the premise underlying marriage, namely that a marital union is, conceptually permanent.

22 Equations (7) and (8) are the same as the ' $\mathrm{H}$ alf-Sibling Rule' used in rewrite rule analysis.

23 Equations (9)-(14) are considered axiomatic by Scheffler and Lounsbury: 'It may be regarded as an axiom of all kinship systems we know of that, e.g. the parent of a sibling is a parent or step-parent, and conversely, the sibling of a child is a child or step-child. Similarly, the sibling of a sibling is regarded as a sibling . . .' (1971: 128, note).

24 It should benoted that the genealogical grid and the structure referred to by Lehman and W itz, (1974) as the Primary G enealogical Space (PGS) (see also, Lehman, this issue: note 1) are not isomorphic. Whereas PGS is (roughly) a product structure based on four relations that ensure consistency with genealogical tracing (see D efinition 2.2, Lehman and Witz, 1974), the genealogical grid is a homomorphic image of PGS whose structure is reduced from the structure of PG S via Equations (9-14). Lehman provides the useful clarification that PGS 'is the cognitive space within which, alone, such reckoning [i.e. genealogical tracing] is to be understood' (Lehman, this issue: note 10).

\section{References}

Atkins, J.R. (1974) 'On the Fundamental C onsanguineal N umbers and Their

Structural Basis', American Ethnologist 1: 1-31. 
READ Formal analysis of kinship terminologies

Austen, L. (1934) 'Procreation among the Trobriand Islanders', 0 ceania 5: 112-13.

Beattie, J. (1964) 'K inship and Social Anthropology', M an, n.s. 13: 475- 76.

Behrens, C. (1984) 'Shipibo Ecology and Economy. D issertation: University of California, Los Angeles.

Bourdieu, P. (1990) The Logic of Practice. (R. N ice, trs.) Stanford, CA:.Stanford University Press.

Buchler, I. and H. Selby (1968) Kinship and Social O rganization: An Introduction to Theory and M ethod. N ew York: The M acmillan Company.

Chomsky, N . (1963) 'Formal Properties of Grammars', in R.D. Luce, R.R. Bush and E. G alanter (eds) $\mathrm{H}$ andbook of M athematical Psychology, Vol. 2, pp. 323-41. N ew York: Addison Wesley.

D 'andrade, R. (1970) 'Structure and Syntax in the Semantic Analysis of Kinship Terminologies', in P.L. Garvin (ed.) Cognition: A M ultipleView, pp. 87-143. N ew York: Spartan Books.

Fortes, M . (1969) Kinship and the Social Order. N ew York: Aldine Publishing Co.

Goodale, J. (1994 /1971) Tiwi Wives. Prospect H eights, IL: Waveland Press.

Goodenough, W. (1970) D escription and Comparison in Cultural Anthropology. Cambridge: C ambridge University Press.

$\mathrm{H}$ elmig, T. (1998) 'T he Concept of Kinship in Yap and the D iscussion of the Concept of Kinship', Journal of Anthropological Research 53: 1-15.

H irschfeld, L.A. (1986) 'Kinship and Cognition: Genealogy and the M eaning of Kinship Terms', Current Anthropology 27: 217-42.

Kelly, R.C. (1974) Etoro Social Structure: A Study in Structural Contradiction. Ann Arbor: University of M ichigan Press.

K ronenfeld, D . (1980) 'Particularistic or Universalistic Analyses of Fanti Kinterminology: The Alternative G oals of Terminological Analysis', M an 15:151-69.

Langness, L.L. (1964) 'Some Problems in the Conceptualization of H ighlands Social Structures', American Anthropologist 66: 162-82.

Leach, E.R. (1958) 'C oncerning Trobriand Clans and the Kinship C ategory "Tabu" ', in J. Goody (ed.) The D evelopmental Cycle in D omestic G roups, pp. 120-45. Cambridge: Cambridge U niversity Press.

Leach, E.R. (1966) 'Virgin Birth', Proceedings of the Royal Anthropological Institute, 39- 49.

Leaf, M . (1971) 'T he Punjabi Kinship Terminology as a Semantic System', American Anthropologist 73: 545-54.

Lehman, F.K. and K. W itz (1974) 'Prolegomena to a Formal Theory of Kinship', in P. Ballonoff (ed.) Genealogical M athematics, pp. 111-34. Paris: M outon.

Lounsbury, F. (1965) 'Another View of the Trobriand Kinship Categories', in E. A. $\mathrm{H}$ ammel (ed.) 'Formal Semantic Analysis', American Anthropologist, Special Publication 62(5), Part 2 142-85.

M alinowski, B. (1913) The Family among the Australian Aborigines. London: U niversity of London Press.

M alinowski, B. (1932) The Sexual Life of Savages in N orth-Western M elanesia, 3rd edition. London: Routledge and Sons.

M arshall, L. (1976) The !Kung of N yae N yae. C ambridge, M A: H arvard U niversity Press. 
M axwell, J. (1996) 'K in Terminology of an Inuit Community', in R. J. DeM allie and A. O rtiz (eds) N orth American Indian Anthropology: Essays on Society and Culture, pp. 25-48. N orman: U niversity of O klahoma Press.

M CD ougal, C. (1964) 'Juang Categories and Joking Relationships', Southwestern Journal of Anthropology 20: 207-30.

N eedham, R. (1962) 'G enealogy and C ategory in W ikmumkan Society', Ethnology 1: 223-64.

N eedham, R. (1971) 'Introduction', in R. N eedham (ed.) Rethinking Kinship and M arriage, pp. xiii-cxvii. London: Tavistock.

Parkin, R. (1996) 'G enealogy and Category: An 0 perational View', L'H omme 139: 87-108.

Powell, H .S. (1956) 'An Analysis of Present D ay Social Structure in the Trobriand Islands'. D issertation: University of London.

Read, D . (1984) 'An Algebraic Account of the American Kinship Terminology', Current Anthropology 25: 417-40.

Read, D . (1990) 'T he U tility of M athematical Constructs in Building Archaeological Theory', in A. Voorrips (ed.) M athematics and Information Science in Archaeology: A FlexibleFramework, pp. 29-60. Bonn: H elos.

Read, D. (2001) 'W hat is Kinship?', in R. Feinberg and M . Ottenheimer (eds) The Cultural Analysis of Kinship: The L egacy of D avid Schneider and Its Implications for Anthropological Relativism. U rbana: U niversity of Illinois Press.

Read, D. (n.d.) The Kinship Algebra Expert System Software Program. M anuscript.

Read, D and C. Behrens (1990) 'KAES: An Expert System for the Algebraic Analysis of Kinship Terminologies', Journal of Q uantitative Anthropology 2: 353-93.

Rivers, W.H .R. (1924) Social Organization. London: W.J. Perry.

Scheffler, H.W. (1978) Australian Kin Classification. Cambridge: Cambridge U niversity Press.

Scheffler, H .W and F. Lounsbury (1971) A Study in Structural Semantics: The Siriono Kinship System. Englewood Cliffs, N J: Prentice H all.

Schneider, D. (1980) American Kinship: A Cultural Account. Englewood Cliffs, N J: Prentice-H all.

Schneider, D. (1984) A Critique of the Study of Kinship. Ann Arbor: University of M ichigan Press.

Singarimbun, M . (1975) Kinship, D escent, and Alliance among the Karo Batak. Berkeley: U niversity of $C$ alifornia Press.

Southwold, M . (1971) 'M eanings of Kinship', in R. N eedham (ed.) Rethinking Kinship and $M$ arriage, pp. 35-56. London: Tavistock Publications.

Strathern, A. (1972) O neFather, O ne Blood. London: Tavistock Publications.

Strathern, A. (1973) 'K inship, D escent and Locality: Some N ew Guinea Examples', in J. Goody (ed.) The Character of Kinship, pp. 21-34. Cambridge: Cambridge University Press.

Strathern, M . (1992) 'K inship Assisted', in M. Strathern (ed.) Reproducing the Future: Essays on Anthropology, Kinship and the N ew Reproductive Technologies, pp. 14-30. $M$ anchester: $M$ anchester University Press.

Strehlow, T.G.H . (1971) Song of Central Australia. Sydney: Angus and Robertson. 
READ Formal analysis of kinship terminologies

Vatuk, S. (1969) 'A Structural Analysis of the H indi Kinship Terminology', Contributions to Indian Sociology, n.S., 3: 94-115.

DWIGH T W. READ received his PhD in mathematics on properties of abstract algebras. He is a Professor of Anthropology and of Statistics and publishes in all of the subfields of anthropology (statistical modeling of hominid evolution, theory and method of artifact classification, formal representation of cultural constructs, and currently kinship terminologies). He has edited two Special Issues of the Journal of Q uantitative Anthropology - Computer-Based Solutions to Anthropological Problems (1990) and Formal M ethods in Anthropology: Past Successes and N ew D irections (1993) - and a Special Issue of the Journal of Artificial Societies and Social Simulation (Computer Simulation in Anthropology). He has developed a major computer program (Kinship Algebraic Expert System, or KAES) that constructs a formal (algebraic) model of the logic underlying the structure of a kinship terminology. $\mathrm{H}$ is current research focuses on the interrelationship between the material and the ideational domains in human societies. Address: D epartment of Anthropology and D epartment of Statistics, University of California, Los Angeles, USA. [email: dread@anthro.ucla.edu] 
